\title{
ERROR ANAL YSIS DALAM PENULISAN MENU DITINJAU DARI SURFACE STRATEGY TAXONOMY PADA MAHASISWA STIPAR TRIATMA JAYA
}

\author{
I Made Agung Rai Antara \\ Sekolah Tinggi Ilmu Pariwisata Triatma Jaya \\ agung.madrid@gmail.com
}

\begin{abstract}
Abstrak
Bahasa Inggris adalah bahasa yang wajib dikuasai oleh mahasiswa terutama di industri perhotelan. Salah satu kemampuan yang wajib dikuasai adalah menjelaskan menu. Menjelaskan menu membutuhkan keterampilan bahasa Inggris yang baik karena jika menggunakan bahasa yang kurang tepat maka makna yang hendak disampaikan pun akan salah. Tujuan penelitian ini adalah mengetahui kesalahan berbahasa mahasiswa STIPAR Triatma Jaya jurusan Manajemen Food and Beverage dalam menulis menu ditinjau dari surface strategy taxonomy. Keempat taxonomy tersebut yaitu omission, addition, misinformation, dan misordering. Penelitian ini adalah penelitian deskriptif dengan jumlah sampel tulisan sebanyak 34 buah. Data dikumpulkan melalui dokumentasi dan wawancara. Penelitian ini menggunakan teori Surface strategy taxonomy yang dikemukakan oleh Dulay,dkk. Hasil penelitian menunjukkan bahwa kesalahan yang paling banyak ditemukan adalah addition sebesar $47,01 \%$, kedua misinformation dengan presentase 28,21 , ketiga omission 19,66 dan yang paling sedikit adalah misordering $3,42 \%$. Hambatan-hambatan yang dihadapi dalam menulis menu adalah merangkai ide dalam bahasa Inggris, terbatasnya kosakata dan tata bahasa.
\end{abstract}

Kata Kunci : Kesalahan berbahasa, Menu, Surface strategy taxonomy

\section{PENDAHULUAN}

Bahasa merupakan alat komunikasi yang sangat penting. Melalui bahasa, manusia bisa berkomunikasi dengan manusia lainnya dengan baik. Komunikasi melibatkan pertukaran informasi yang disampaikan dalam ada dua jenis yaitu lisan dan tulisan. Kelancaran penyampaian informasi dari satu sumber bahasa dengan penerima bahasa tergantung dari kejelasan informasi yang diterima. Hal-hal yang mempengaruhi kelancaran informasi yang disampaikan beberapa diantaranya adalah tata bahasa dan kosakata. Melalui tata bahasa dan penguasaan kosakata yang baik, bahasa yang disampaikan pun akan lebih mudah dimengerti. Bahasa yang dipelajari manusia terus berkembang setiap tahunnya. Bahasa Inggris dipergunakan dan tersebar kurang lebih satu per empat dari penduduk dunia. Diperkirakan jumlah ini akan terus bertambah menjadi 1,5 triliyun pada tahun 2000 an ini (Crystal, 2003). Maka dari itu bahasa Inggris mampu 
merambah berbagai sektor termasuk dunia pendidikan.

Bahasa Inggris adalah salah satu mata kuliah wajib di Perguruan Tinggi. Pelajaran yang diberikan mulai dari bahasa Inggris umum sampai bahasa Inggris profesi. Empat skill yang diajarkan adalah speaking, listening, reading and writing. Sebagai mata kuliah yang sangat menunjang kemampuan dalam bidang perhotelan maupun pariwisata, bahasa Inggris memiliki peranan yang sangat penting mengingat melalui bahasa Inggris mahasiswa bisa menyampaikan atau memperoleh informasi dan menguasai ilmu perhotelan yang lain dengan mudah. Salah satu contoh adalah keterampilan dalam menjelaskan menu dalam bahasa Inggris.

Kemampuan menjelaskan menu dalam bahasa Inggris merupakan suatu keterampilan yang menguji kemampuan siswa untuk mendeskripsikan makanan tertentu dengan lancar dan jelas. Menu merupakan salah satu teks deskriptif karena di dalam menu ada penjelasan rinci bagaimana makanan tersebut dibuat. Penulis teks deskripsi dapat menggambarkan sesuatu pada pembaca sehingga pembaca mampu melihat, mendengar, dan mencium apa yang digambarkan Suparno dan Yunus (2006: 46). Supaya pembaca bisa mengerti gambaran yang dibuat oleh penulis, maka diperlukan penguasaan tata bahasa yang baik. Kurangnya pemahaman mahasiswa terhadap tata bahasa sering menimbulkan kesalahan berbahasa. Hal ini disebabkan karena pengguna bahasa keliru dalam menerapkan kaidah bahasa, akibatnya pada penulisan menu seringkali dijumpai kesalahan berbahasa sehingga makna tulisan pada deskripsi menu tidak bisa dimengerti dengan baik.

Penelitian ini berfokus pada kesalahan berbahasa yang dibuat oleh mahasiswa jurusan manajemen food and beverage dalam mendeskripsikan menu ditinjau dari surface strategi taxonomy. Melalui penelitian ini, penulis ingin mengetahui jenis eror yang dilakukan mahasiswa yaitu dari segi omission, addition, misinformation, dan misordering dan hambat-hambatan yang dihadapi mahasiswa dalam menulis menu.

Dalam pengajaran bahasa dikenal istilah kesalahan (eror) dan kekeliruan (mistake). Kesalahan berbahasa disebabkan oleh pemahaman, kemampuan atau kompetensi, Kesalahan ini selalu berulang, sistematis dan konsisten. Sedangkan kekeliruan bersifat acak dan individual, tidak sistematis dan bersifat sementara (Tarigan,1997) Pendapat lain juga menyebutkan definisi eror adalah kesalahan berbahasa oleh penutur bahasa karena tidak mengikuti kaidah tata bahasa (breaches of code). Hal ini terjadi karena kaidah tata bahasa penutur berbeda dengan aturan bahasa lain. Hal ini menyebabkan ketidakmampuan dan kekurangsempurnaan penutur dalam menggunakan bahasa sehingga terjadi kesalahan berbahasa karena penutur menggunakan aturan bahasa yang kurang tepat (Corder, 1974).

Selanjutnya Dulay,Burt dan Krashen menyebutkan eror adalah kejanggalan yang dibuat pembelajar dalam ucapan atau tulisan. Salah satu klasifikasi deskriptif dari eror adalah Surface Strategy Taxonomy. 
Taxonomi ini menganalisa kesalahan yang dibuat oleh pembelajar bahasa yang terdiri dari beberapa 4 klasifikasi eror. Eror tersebut adalah omission, addition,

Berdasarkan latar belakang masalah diatas, maka ada dua permasalahan yang dapat dirumuskan,yaitu: (1)Tipe-tipe kesalahan apa saja yang dilakukan mahasiswa pada saat mendeskripsikan menu dalam bahasa Inggris dilihat dari surface stucture taxonomy? (2) Hambatanhambatan apa saja yang dihadapi oleh mahasiswa jurusan food and beverage ketika mereka menulis deskripsi menu dalam bahasa Inggris?

Penelitian ini memiliki dua tujuan. Tujuan penelitian ini adalah (1) Mengetahui tipe-tipe kesalahan yang dilakukan mahasiswa pada saat mendeskripsikan menu dalam bahasa Inggris berdasarkan surface structure taxonomy (2) Mengetahui hambatan-hambatan yang dihadapi mahasiswa ketika menulis deskripsi menu? misinformation, dan misordering. Keempat jenis taksonomi dan contohnya dapat dilihat pada tabel dibawah ini.

\section{METODE}

Penelitian ini adalah penelitian deksriptif. Semua kesalahan yang dilakukan oleh mahasiswa STIPAR Triatma Jaya pada penulisan menu diklasifikasikan menggunakan surface strategy taxonomy yang dikemukakan oleh Dulay, dkk. Data tersebut kemudian dijelaskan secara detail dan diperbaiki. Data diambil dari tulisan mahasiswa jurusan manajemen food and beverage sebanyak 34 tulisan. Setiap tulisan memuat lima menu yang dideskripsikan secara tertulis. Menu-menu tersebut adalah Fuyung hai, Fried rice, Ayam Betutu, Rujak, dan Sate.

\section{HASIL DAN PEMBAHASAN}

Hasil analisis Surface Strategy Taxonomy pada menu yang ditulis oleh mahasiswa STIPAR Triatma Jaya dapat dilihat pada tabel dibawah ini.

\begin{tabular}{|l|l|l|}
\hline No & \multicolumn{1}{|c|}{ Surface Strategy Taxonomy } & \multicolumn{1}{|c|}{ Presentase } \\
\hline 1 & Addition & $47,01 \%$ \\
\hline 2 & Omission & $19,66 \%$ \\
\hline 3 & Misinformation & $28,21 \%$ \\
\hline 4 & Misordering & $3,42 \%$ \\
\hline
\end{tabular}

Hasil analisis terhadap karangan mahasiswa ditinjau dari surface strategi taxonomy mendeskripsikan bahwa Addition eror menempai posisi pertama dengan jumlah 47,01\%. Kesalahan terbanyak kedua ditempati oleh misinformation sebanyak 28,21\%. Kesalahan terbesar ketiga ditempati oleh omission error dengan jumlah 19,66\% dan posisi terakhir 
ditempati oleh misordering dengan jumlah 3,42\%. Contoh eror yang dilakukan di masingmasing taksonomi dapat dilihat pada tabel berikut ini.

Pada tabel dibawah ini adalah contoh addition eror yang dilakukan oleh mahasiswa STIPAR Triatma Jaya jurusan Food and Beverage. Kesalahan yang dilakukan adalah lebih dominan pada kesalahan double subject it, preposisi of, dan artikel a.

\begin{tabular}{|c|c|c|c|}
\hline No & Contoh kesalahan & Perbaikan & Deskripsi surface structure \\
\hline 1 & $\begin{array}{l}\text { Fuyung hai it is a } \\
\text { hot appetizer made } \\
\text { from egg, celery, } \\
\text { leek, salt, pepper, } \\
\text { sweet sour sauce } \\
\text { sweet sour sauce } \\
\text { made from tomato } \\
\text { sauce, egg wash, } \\
\text { garlic, water, salt } \\
\text { and pepper }\end{array}$ & $\begin{array}{l}\text { Fuyung hai is hot appetizer } \\
\text { made from egg, celery, leek, } \\
\text { salt, pepper, and sweet sour } \\
\text { sauce. Sweet sour sauce is } \\
\text { made from tomato sauce, egg } \\
\text { wash, garlic, water, salt, and } \\
\text { pepper }\end{array}$ & Addition \\
\hline 2 & $\begin{array}{l}\text { Sate it is main } \\
\text { course made from } \\
\text { diced chicken, and } \\
\text { peanut sauce }\end{array}$ & $\begin{array}{l}\text { Sate is main course made from } \\
\text { diced chicken and peanut sauce }\end{array}$ & Addition \\
\hline 3 & $\begin{array}{l}\text { Sweet sour made } \\
\text { from tomato sauce, } \\
\text { tomato fresh, rice } \\
\text { flour, and little bit } \\
\text { of spicy powder }\end{array}$ & $\begin{array}{l}\text { Sweet sour made from tomato } \\
\text { sauce, tomato fresh, rice flour, } \\
\text { and little bit spicy powder }\end{array}$ & Addition \\
\hline 4 & $\begin{array}{l}\text { Fuyung hai is a } \\
\text { appetizer make } \\
\text { from egg, vegetable } \\
\text { like a cabbage, salt, } \\
\text { pepper, celery. }\end{array}$ & $\begin{array}{l}\text { Fuyung hai is appetizer made } \\
\text { from egg, vegetable like } \\
\text { cabbage, salt, pepper, and } \\
\text { celery }\end{array}$ & Addition \\
\hline 5 & $\begin{array}{l}\text { Rujak is a } \\
\text { appetizer make } \\
\text { from fruits like a } \\
\text { papaya, mango, } \\
\text { guava, and mix with } \\
\text { sugar, shrimp paste, } \\
\text { salt }\end{array}$ & $\begin{array}{l}\text { Rujak is appetizer made from } \\
\text { fruits such as a papaya, } \\
\text { mango, guava, and mix with } \\
\text { sugar, shrimp paste and salt }\end{array}$ & Addition \\
\hline 6 & $\begin{array}{l}\text { Fuyung hai it is } \\
\text { Chinese food made } \\
\text { from egg, carrot, }\end{array}$ & $\begin{array}{l}\text { Fuyung hai is Chinese food } \\
\text { made from egg, carrot, garlic } \\
\text { chicken, leek, serve with steam }\end{array}$ & Addition \\
\hline
\end{tabular}




\begin{tabular}{|c|c|c|c|}
\hline & $\begin{array}{l}\text { garlic chicken, leek, } \\
\text { serve with steam } \\
\text { rice }\end{array}$ & rice & \\
\hline 7 & $\begin{array}{l}\text { Ayam betutu it is } \\
\text { Balinese food made } \\
\text { from chicken and } \\
\text { Balinese spice } \\
\text { made from shallot, } \\
\text { garlic, ginger, } \\
\text { turmeric, salt and } \\
\text { pepper, chili, lemon } \\
\text { grass and oil. }\end{array}$ & $\begin{array}{l}\text { Ayam betutu is Balinese food } \\
\text { made from chicken and } \\
\text { Balinese spice made from } \\
\text { shallot, garlic, ginger, turmeric, } \\
\text { salt and pepper, chili, lemon } \\
\text { grass and oil. }\end{array}$ & Addition \\
\hline 8 & $\begin{array}{l}\text { Fuyung hai is a hot } \\
\text { appetizer made } \\
\text { from egg, carrot, } \\
\text { Chinese cabbage, } \\
\text { leek, serve with } \\
\text { Fuyung hai sauce. }\end{array}$ & $\begin{array}{l}\text { Fuyung hai is hot appetizer } \\
\text { made from egg, carrot, Chinese } \\
\text { cabbage, leek, serve with } \\
\text { Fuyung hai sauce. }\end{array}$ & Addition \\
\hline 9 & $\begin{array}{l}\text { Fried rice is a main } \\
\text { course made from } \\
\text { steam rice, carrot, } \\
\text { leek, Chinese } \\
\text { cabbage, egg, } \\
\text { shallot, garlic, } \\
\text { tomato ketchup, } \\
\text { sweet soya sauce, } \\
\text { fish gravy, oyster } \\
\text { sauce, garnish with } \\
\text { fried shallot. }\end{array}$ & $\begin{array}{l}\text { Fried rice is main course } \\
\text { made from steamed rice, carrot, } \\
\text { leek, Chinese cabbage, egg, } \\
\text { shallot, garlic, tomato ketchup, } \\
\text { sweet soya sauce, fish gravy, } \\
\text { oyster sauce, and garnish with } \\
\text { fried shallot. }\end{array}$ & Addition \\
\hline 10 & $\begin{array}{l}\text { Fuyung hai is a } \\
\text { Chinese dish made } \\
\text { from egg that are } \\
\text { mixed with } \\
\text { vegetables and } \\
\text { meat }\end{array}$ & $\begin{array}{l}\text { Fuyung hai is Chinese dish } \\
\text { made from egg that are mixed } \\
\text { with vegetables and meat }\end{array}$ & Addition \\
\hline
\end{tabular}

Pada omission eror, kebanyakan kesalahan terletak pada kesalahan tobe dan subjek. Secara lengkap kalimat yang menunjukkan omission dapat dilihat pada contoh kalimat dibawah ini.

\begin{tabular}{|l|l|l|l}
\hline 1 & Bumbu Rajang Bali & Bumbu Rajang Bali is made & Ommision
\end{tabular}




\begin{tabular}{|c|c|c|c|}
\hline & $\begin{array}{l}\text { made from shallot, } \\
\text { garlic, ginger, } \\
\text { galangal, turmeric, } \\
\text { egg, chili, black } \\
\text { pepper, white } \\
\text { pepper, and blend } \\
\text { until smooth and } \\
\text { marinade whole } \\
\text { chicken served with } \\
\text { steam rice and urab } \\
\text { sayur }\end{array}$ & $\begin{array}{l}\text { from shallot, garlic, ginger, } \\
\text { galangal, turmeric, egg, chili, } \\
\text { black pepper, white pepper, and } \\
\text { blend until smooth and } \\
\text { marinade chicken whole } \\
\text { served with steam rice and urab } \\
\text { sayur }\end{array}$ & \\
\hline 2 & $\begin{array}{l}\text { Sauce rujak made } \\
\text { from brown sugar, } \\
\text { chili, salt, shrimp } \\
\text { paste, and water }\end{array}$ & $\begin{array}{l}\text { Sauce rujak is made from } \\
\text { brown sugar, chili, salt, shrimp } \\
\text { paste, and water }\end{array}$ & Omission \\
\hline 3 & $\begin{array}{l}\text { Rujak is appetizer } \\
\text { made from Java. } \\
\text { Made from peanut } \\
\text { sauce and } \\
\text { accompaniments } \\
\text { are fried tofu, fried } \\
\text { tempe with shape is } \\
\text { long circle. }\end{array}$ & $\begin{array}{l}\text { Rujak is appetizer made from } \\
\text { Java. It is made from peanut } \\
\text { sauce and accompaniments } \\
\text { are fried tofu, fried tempe, and } \\
\text { long circled soft rice }\end{array}$ & Omission \\
\hline 4 & $\begin{array}{l}\text { Rujak appetizer } \\
\text { made from sliced } \\
\text { fruit }\end{array}$ & $\begin{array}{l}\text { Rujak is appetizer made from } \\
\text { sliced fruit }\end{array}$ & Omission \\
\hline 5 & $\begin{array}{l}\text { Rujak cold dessert } \\
\text { made from sliced } \\
\text { mango, sliced } \\
\text { bengkoang, sliced } \\
\text { cucumber, salt, } \\
\text { sugar, chili and } \\
\text { kuah pindang }\end{array}$ & $\begin{array}{l}\text { Rujak is cold dessert made } \\
\text { from sliced mango, sliced } \\
\text { bengkoang, sliced cucumber, } \\
\text { salt, sugar, chili and kuah } \\
\text { pindang }\end{array}$ & Omission \\
\hline 6 & $\begin{array}{l}\text { Sate hot main } \\
\text { course made from } \\
\text { dice chicken, peanut } \\
\text { sauce and sauce } \\
\text { with peanut sauce }\end{array}$ & $\begin{array}{l}\text { Sate is hot main course made } \\
\text { from diced chicken and peanut } \\
\text { sauce }\end{array}$ & Omission \\
\hline 7 & $\begin{array}{l}\text { Ayam betutu from } \\
\text { main course made } \\
\text { from chicken whole }\end{array}$ & $\begin{array}{l}\text { Ayam betutu is main course } \\
\text { made from chicken whole and } \\
\text { Balinese spice. }\end{array}$ & Omission \\
\hline
\end{tabular}




\begin{tabular}{|c|c|c|c|}
\hline & and Balinese spice. & & \\
\hline 8 & $\begin{array}{l}\text { Sate from main } \\
\text { course made from } \\
\text { chicken and peanut } \\
\text { sauce }\end{array}$ & $\begin{array}{l}\text { Sate is main course made } \\
\text { from chicken and peanut sauce }\end{array}$ & Omission \\
\hline 9 & $\begin{array}{l}\text { Method of cooking } \\
\text { frying }\end{array}$ & Method of cooking is frying & Omission \\
\hline 10 & $\begin{array}{l}\text { Method of cooking } \\
\text { blanching }\end{array}$ & Method of cooking is blanching & Omission \\
\hline 11 & $\begin{array}{l}\text { Rujak can clarified } \\
\text { to cold appetizer but } \\
\text { sometimes Balinese } \\
\text { people eat rujak } \\
\text { after they eat main } \\
\text { course }\end{array}$ & $\begin{array}{l}\text { Rujak can be clarified to cold } \\
\text { appetizer but sometimes } \\
\text { Balinese people eat rujak after } \\
\text { they eat main course }\end{array}$ & Omission \\
\hline
\end{tabular}

Pada misinformation eror kesalahan yang paling banyak dilakukan adalah pada pembentukan adjective. Contoh misinformation dapat dilihat pada contoh dibawah ini.

\begin{tabular}{|l|l|l|l|}
\hline 1 & $\begin{array}{l}\text { It is main course } \\
\text { form indonesian } \\
\text { menu made from } \\
\text { steam rice, } \\
\text { chicken, garlic, } \\
\text { onion, green } \\
\text { vegetable }\end{array}$ & $\begin{array}{l}\text { It is main course form } \\
\text { indonesian menu made from } \\
\text { steamed rice, chicken, garlic, } \\
\text { onion, green vegetable }\end{array}$ & Misinformation \\
\hline 2 & $\begin{array}{l}\text { It is appetizer made } \\
\text { from mix fruits, } \\
\text { mango, pine apple } \\
\text { papaya }\end{array}$ & $\begin{array}{l}\text { It is appetizer made from mixed } \\
\text { fruits, mango, pine apple } \\
\text { papaya }\end{array}$ & Misinformation \\
\hline 3 & $\begin{array}{l}\text { It is Indonesian } \\
\text { menu made from } \\
\text { grill of chicken } \\
\text { satay marinade with } \\
\text { salt and sweet soya } \\
\text { sauce }\end{array}$ & $\begin{array}{l}\text { It is Indonesian menu made } \\
\text { from grilled chicken satay } \\
\text { marinade with salt and sweet } \\
\text { soya sauce }\end{array}$ & Misinformation \\
\hline 4 & $\begin{array}{l}\text { It is main course } \\
\text { from indonesian } \\
\text { menu made from } \\
\text { steam rice, } \\
\text { chicken, garlic, } \\
\text { onion, green } \\
\text { vegetable }\end{array}$ & $\begin{array}{l}\text { It is main course from } \\
\text { indonesian menu made from } \\
\text { steamed rice, chicken, garlic, } \\
\text { onion, green vegetable }\end{array}$ & Misinformation \\
\hline
\end{tabular}




\begin{tabular}{|c|c|c|c|}
\hline 5 & $\begin{array}{l}\text { It is main course } \\
\text { made from garlic, } \\
\text { egg, carrot, white } \\
\text { cabbage, steam } \\
\text { rice serve with fried } \\
\text { chicken and } \\
\text { crackers }\end{array}$ & $\begin{array}{l}\text { It is main course made from } \\
\text { garlic, egg, carrot, white } \\
\text { cabbage, steamed rice serve } \\
\text { with fried chicken and crackers }\end{array}$ & Misinformation \\
\hline 6 & $\begin{array}{l}\text { Fuyung hai is main } \\
\text { course make of } \\
\text { egg, flour, leek, and } \\
\text { cabbage serve with } \\
\text { sauce. }\end{array}$ & $\begin{array}{l}\text { Fuyung hai is main course } \\
\text { made from egg, flour, leek, and } \\
\text { cabbage serve with sauce. }\end{array}$ & Misinformation \\
\hline 7 & $\begin{array}{l}\text { Fried rice is main } \\
\text { course make of } \\
\text { rice, vegetable, egg, } \\
\text { tomato ketchup, } \\
\text { sweet soya sauce, } \\
\text { salt and pepper, } \\
\text { served with fried } \\
\text { egg on the top }\end{array}$ & $\begin{array}{l}\text { Fried rice is main course made } \\
\text { from rice, vegetable, egg, } \\
\text { tomato ketchup, sweet soya } \\
\text { sauce, salt and pepper, served } \\
\text { with fried egg on the top }\end{array}$ & Misinformation \\
\hline 8 & $\begin{array}{l}\text { Rujak is appetizer } \\
\text { make of mix fruit } \\
\text { and mix with brown } \\
\text { sugar sauce }\end{array}$ & $\begin{array}{l}\text { Rujak is appetizer made from } \\
\text { mixed fruit and brown sugar } \\
\text { sauce }\end{array}$ & Misinformation \\
\hline 9 & $\begin{array}{l}\text { Sate is main course } \\
\text { make of chicken of } \\
\text { beef, mix with } \\
\text { peanut sauce. }\end{array}$ & $\begin{array}{l}\text { Sate is main course made of } \\
\text { chicken or beef, mixed with } \\
\text { peanut sauce. }\end{array}$ & Misinformation \\
\hline 10 & $\begin{array}{l}\text { Fuyung hai from } \\
\text { appetizer made } \\
\text { from egg, carrot, } \\
\text { cabbage, flour, leek, } \\
\text { and Chinese sauce }\end{array}$ & $\begin{array}{l}\text { Fuyung hai is one of appetizer } \\
\text { made from egg, carrot, } \\
\text { cabbage, flour, leek, and } \\
\text { Chinese sauce }\end{array}$ & Misinformation \\
\hline
\end{tabular}

Contoh Misordering error dapat dilihat pada contoh dibawah ini:

\begin{tabular}{|l|l|l|l|}
\hline 1 & $\begin{array}{l}\text { It is fried eggs made } \\
\text { from eggs, leek, carrot, } \\
\text { red chili, maizena, } \\
\text { garlic, salt and pepper, } \\
\text { served with sauce } \\
\text { asam manis }\end{array}$ & $\begin{array}{l}\text { It is fried eggs made from } \\
\text { eggs, leek, carrot, red chili, } \\
\text { maizena, garlic, salt and } \\
\text { pepper, served with asam } \\
\text { manis sauce }\end{array}$ & Misordering \\
\hline 2 & It is dessert made from & It is dessert made from fruit & Misordering \\
\hline
\end{tabular}




\begin{tabular}{|c|c|c|c|}
\hline & fruit cutting cube & which is cut into cube & \\
\hline 3 & $\begin{array}{l}\text { Frie rice is a main } \\
\text { course made from } \\
\text { chicken whole }\end{array}$ & $\begin{array}{l}\text { Frie rice is a main course } \\
\text { made from whole chicken }\end{array}$ & Misordering \\
\hline 4 & $\begin{array}{l}\text { Fried rice from main } \\
\text { course made from rice, } \\
\text { carrot, cabbage slice, } \\
\text { tomato slice, sweet } \\
\text { soy sauce, oyster } \\
\text { sauce and chicken } \\
\text { boiled }\end{array}$ & $\begin{array}{l}\text { Fried rice is main course } \\
\text { made from rice, carrot, sliced } \\
\text { cabbage, slice tomato, sweet } \\
\text { soy sauce, oyster sauce and } \\
\text { boiled chicken }\end{array}$ & Misordering \\
\hline
\end{tabular}

\section{PENUTUP}

Menulis menu merupakan kegiatan yang membutuhkan keterampilan berbahasa yang baik. Seringkali karena keterbatasan penguasaan terhadap tata bahasa, mahasiswa melakukan kesalahan berbahasa atau eror. Kesalahan berbahasa dapat dilihat dari berbagai segi. Salah satunya adalah surface strategi taxonomy. Taksonomi ini menelaah eror dari segi addition, omission, misinformation, dan misordering. Berdasarkan hasil analisis yang dilakukan pada mahasiswa jurusan manajemen food and beverage, dapat diperoleh kesimpulan bahwa kesalahan yang mendominasi adalah addition, diikuti oleh misinformation, ketiga omission dan yang paling sedikit adalah misordering. Hambatan-hambatan mahasiswa dalam menulis menu dalam bahasa Inggris adalah kurangnya penguasaan tentang tata bahasa dan penguasaan kosakata yang masih minim. Tata bahasa bahasa Inggris memiliki struktur yang kompleks, sehingga mahasiswa membutuhkan waktu yang cukup lama untuk menerapkan pengetahuan ke dalam bentuk tulisan. Pengetahuan mahasiswa tentang bahasa Inggris masih perlui ditingkatkan lagi walaupun mahasiswa sudah belajar bahasa Inggris dari sd sampai perguruan tinggi. Kemampuan mahasiswa tidak berkembang karena mempelajari materi kuliah yang banyak, sehingga waktu untuk mempelajari bahasa inggris sangat minim. Kendala lainnya adalah kurangnya frekuensi mahasiswa berbicara bahasa inggris baik itu dikelas maupun di kehidupan seharihari.

Berikut ini adalah saran-saran yang bisa diberikan terkait dengan analisis eror pada penulisan menu yang dibuat mahasiswa STIPAR Triatma Jaya jurusan Food and Beverage.

Mahasiswa perlu diberikan latihan tentang menjelaskan menu sebanyak mungkin. Mulai dari appetizer, soup, main course dan dessert. Menu yang diberikan harus bervariasi mulai dari Negara yang berbeda-beda misalnya Jepang, India, dan Eropa. Latihan ini akan bermanfaat untuk 
melatih mahasiswa menulis dan berbicara tentang menu yang sering disajikan di restoran sehingga kapanpun mereka ditanya tentang menu mereka sudah siap menjelaskan dengan bahasa yang baik dan benar..

Mahasiswa perlu memahami tentang addition, misinformation, omission, dan misordering. Mahasiswa perlu diberikan latihan tambahan dalam kosakata dan tata bahasa sehingga kalimat yang disampaikan mahasiswa kepada tamu nantinya dapat dimengerti dengan baik.

\section{DAFTAR RUJUKAN}

Corder, S.P. (1974). Error Analysis and Interlanguage. Oxford: Oxford University Press.

Crystal, David. (2003). English as a Global Language. New York: Cambridge University Press

Suparno dan Yunus, Muhammad. (2004). Keterampilan Dasar Menulis. Jakarta:

Tarigan, Guntur H.(1997). Analisis Kesalahan Berbahasa. Jakarta : Depdikbud 